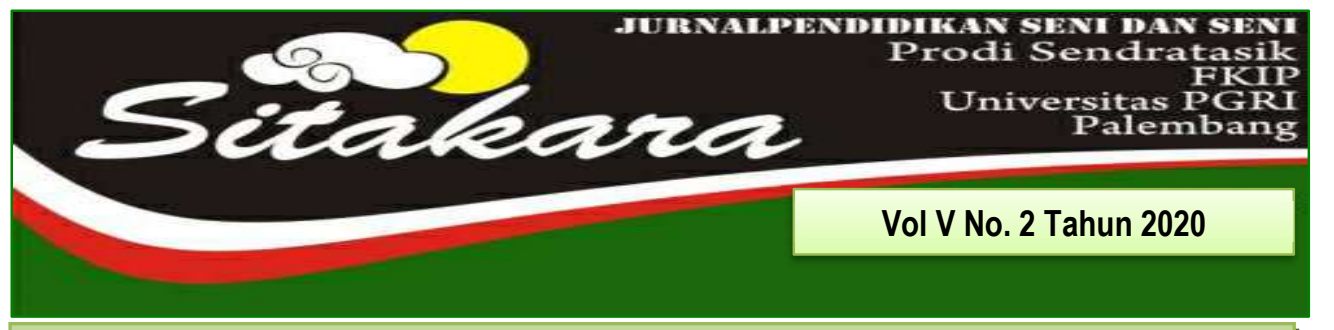

FUNGSI DAN MAKNA BHAJAN PADA UPACARA AGAMA HINDU DI KUIL SHRI MARIAMMAN KOTA MEDAN

(Agung Suharyanto, dkk)

KESENIAN SRANDUL DALAM UPACARA BERSIH DESA BULU KALURAHAN KARANGMOJO KECAMATAN KARANGMOJO KABUPATEN GUNUNGKIDUL YOGYAKARTA

(Supriyanto)

FUNGSI DAN MAKNA LAGU GUBANG DALAM UPACARA SIAR MAMBANG PADA MASYARAKAT TANJUNGBALAI

(Theo henry tua siagian ${ }^{1}$, pulumun p. Ginting ${ }^{2} \&$ wiflihani)

FUNGSI TARI MAPAK ADAT MUARA KUANG SEBAGAI TARI SAMBUT

(Nadia Rahma Aprilia', Dessy Wardiah², Treny Hera ${ }^{3}$ )

MAKNA SIMBOLIK RAGAM HIAS PADA RUMAH LIMAS PALEMBANG

(Ferri Hidayad ${ }^{1}$ Decky Kunian ${ }^{2}$ )

GAYA MUSIK SAHILIN DALAM KESENIAN MUSIK BATANGHARI SEMBILAN DI KOTA PALEMBANG

(Feri Firmansyah)

TRANSPOSISI TTI (TRANSFER, TRANSLATION, IMITATE) DALAM PEMBELAJARAN NOTASI MUSIK MELALUI SCORE CREATOR

(A Heryanto ${ }^{1}$ Dedy Firmansyah ${ }^{2}$ )

RASE TAK SERUPE MUSIK MELAYU TRADISI DENGAN PENGEMBANGAN MUSIK MODERN DALAM RUANG PERTUNJUKAN KOMPOSISI MUSIK NUSANTARA (Rio Eka Putra)

BENTUK SYAIR LAGU DALAM PERTUNJUKAN SYAROFAL ANAM DI PEDESTRIAN S UDIRMAN KOTA PALEMBANG

(Nofroza Yelli ${ }^{1}$ Deria Sepdwiko² ${ }^{2}$

"Betenun" Sebuah Wujud Proses Kreatif Mahasiswa Seni Pertunjukan Universitas PGRI PALEMBANG

(Nurdin $^{1}$ Naomi Diah Budi Setyaningrum ${ }^{2}$ ) 
DAFTAR ISI

FUNGSI DAN MAKNA BHAJAN PADA UPACARA AGAMA HINDU DI KUIL 1-15 SHRI MARIAMMAN KOTA MEDAN

(Agung Suharyanto, dkk)

KESENIAN SRANDUL DALAM UPACARA BERSIH DESA BULU KALURAHAN

$16-26$

KARANGMOJO KECAMATAN KARANGMOJO KABUPATEN GUNUNGKIDUL YOGYAKARTA

(Supriyanto)

FUNGSI DAN MAKNA LAGU GUBANG DALAM UPACARA SIAR MAMBANG 27-39 PADA MASYARAKAT TANJUNGBALAI

(Theo henry tua siagian ${ }^{1}$, pulumun $p$. Ginting ${ }^{2} \&$ wiflihani)

FUNGSI TARI MAPAK ADAT MUARA KUANG SEBAGAI TARI SAMBUT

40-52

(Nadia Rahma Aprilia', Dessy Wardiah², Treny Hera')

MAKNA SIMBOLIK RAGAM HIAS PADA RUMAH LIMAS PALEMBANG

53-61

(Ferri Hidayad ${ }^{1}$ Decky Kunian ${ }^{2}$ )

GAYA MUSIK SAHILIN DALAM KESENIAN MUSIK BATANGHARI SEMBILAN DI $\quad 62-76$ KOTA PALEMBANG

(Feri Firmansyah)

TRANSPOSISI TTI (TRANSFER, TRANSLATION, IMITATE) DALAM 77-85 PEMBELAJARAN NOTASI MUSIK MELALUI SCORE CREATOR (A Heryanto ${ }^{1}$ Dedy Firmansyah ${ }^{2}$ )

RASE TAK SERUPE MUSIK MELAYU TRADISI DENGAN PENGEMBANGAN MUSIK MODERN DALAM RUANG PERTUNJUKAN KOMPOSISI MUSIK NUSANTARA

(Rio Eka Putra)

BENTUK SYAIR LAGU DALAM PERTUNJUKAN SYAROFAL ANAM DI PEDESTRIAN SUDIRMAN KOTA PALEMBANG

(Nofroza Yelli ${ }^{1}$ Deria Sepdwiko ${ }^{2}$ )

"BETENUN" SEBUAH WUJUD PROSES KREATIF MAHASISWA SENI

$109-120$ PERTUNJUKAN UNIVERSITAS PGRI PALEMBANG

(Nurdin ${ }^{1}$ Naomi Diah Budi Setyaningrum ${ }^{2}$ )

86-95 


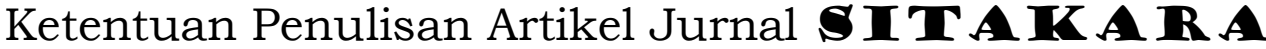

1. Naskah berbahasa Indonesia bertemakan Seni Budaya yang meliputi hasil penelitian pengajaran seni budaya, cabang seni, dan kebudayaan.

2. Naskah harus asli dan belum pernah dimuat dalam media lain. Naskah dapat berupa hasil penelitian perorangan atau kelompok.

3. Naskah ditulis dengan cara-cara yang sesuai dengan ketentuan penulisan artikel ilmiah menggunakan bahasa Indonesia yang baku, berupa ketikan, beserta soft line dalam CD-RW atau dengan mengirimkan email pada redaksi Jurnal SITAKA RA dengan alamat email: jurnalsitakarasendratasik@yahoo.com, spasi 1,5 jenis huruf Arrial Narrow ukuran 12, dengan panjang naskah antara 8-15 halaman pada kertas A4.

4. Artikel hasil penelitian memuat:

JUDUL

Nama Penulis

Abstrak

A. PENDAhuluan

B. METODE PENELITIAN

C. HASIL DAN PEMBAHASAN

D. SIMPULAN

5. Artikel kajian konseptual memuat:

JUDUL

Nama Penulis

Abstrak

PENDAHULUAN
: XXX (HURUF KAPITAL)

: (disertai jabatan dan institusi)

: (Bahasa Indonesia yang memuat 100150 kata diikuti kata kunci, dengan jenis huruf Arrial Narrow dan ukuran huruf 11 spasi tunggal serta dicetak miring)

: (Memuat latar belakang masalah, tinjauan pustaka secara ringkas, masalah penelitian dan tujuan penelitian)

: (Berisi simpulan)

\section{: XXX (HURUF KAPITAL)}

: (disertai jabatan dan institusi)

: (Bahasa Indonesia yang memuat 100150 kata diikuti kata kunci, dengan jenis huruf Arrial Narrow dan ukuran huruf 11 serta dicetak miring)

: (Memuat latar belakang masalah, tinjauan pustaka secara ringkas, 
Sub Judul

Sub Judul

SIMPULAN

DAFTAR PUSTAKA masalah penelitian dan tujuan

penelitian)

: Sesuai dengan kebutuhan (tanpa

numbering)

: (Berisi simpulan dan saran)

: (Berisi pustaka yang dirujuk dalam uraian naskah

6. Referensi sumber dalam teks artikel ditulis dengan menggunakan side note, contoh: (Jalalluddin, 1991:79); (Taufik, 2005;350); (Hamid dan Madjid, 2011:43). Sementara penulisan daftar pustaka disusun dengan ketentuan. Nama Pengarang. Tahun Terbit. Judul (dicetak miring). Kota Terbit: Nama Penerbit. Contoh: Koentjaraningrat. 2010. Manusia dan Kebudayaan Di Indonesia. Jakarta: Djambatan.

Daftar pustaka hanya memuat pustaka/sumber yang dirujuk dalam uraian dan disusun menurut abjad, tanpa nomor urut.

7. Naskah yang dimuat akan disunting kembali oleh redaksi tanpa mengubah isinya.

8. Naskah yang ditolak (tidak bisa dimuat) akan dikirim kembali ke penulis dengan pemberitahuan tertulis dari redaksi atau alamat email.

9. Penulis yang naskahnya dimuat akan mendapatkan 1 (satu) majalah nomor yang bersangkutan.

10. Contact Person: Treny Hera (085357344704) dan Mainur (081373165553). 


\title{
FUNGSI DAN MAKNA LAGU GUBANG DALAM UPACARA SIAR MAMBANG PADA MASYARAKAT TANJUNGBALAI
}

\author{
Oleh: \\ Theo Henry Tua Siagian ${ }^{1}$, Pulumun P. Ginting ${ }^{2}$ \& Wiflihani ${ }^{3}$ \\ (Fakultas Bahasa dan Seni Universitas Negeri Medan Indonesia) \\ Email: wiflihani@unimed.ac.id
}

\begin{abstract}
ABSTRAK
Penelitian ini bertujuan untuk menganalisis kontribusi, fungsi, makna dan tanggapan masyarakat mengenai lagu gubang pada Upacara Siar Mambang di Tanjungbalai, Sumatera Utara. Teori yang digunakan adalah fungsi, makna, Gubang, dan Siar Mambang. Fungsi merupakan kegunaan gubang pada upacara Siar Mambang. Metode penelitian yang digunakan adalah deskriptif kualitatif, sedangkan yang menjadi informan penelitian terdiri dari 13 orang yang terdiri dari tokoh adat 1 orang, pemusik 5 orang, penari 2 orang, masyarakat kota Tanjungbalai 5 orang. Alat yang digunakan untuk pengumpulan data adalah dengan metode observasi, wawancara, dan dokumentasi. Hasil penelitian menunjukkan bahwa Gubang adalah komposisi musik melayu berupa ensambel musik. Siar Mambang adalah upacara pengobatan untuk orang sakit. Dalam susunananya, adanya sebuah lagu yang bertempo semakin cepat untuk menciptakan keadaan trance (kerasukan roh) pada upacara Siar Mambang dan lagu tersebut adalah lagu gubang. Instrumen musik yang dimainkan pada upacara siar mambang ini antara lain gendang, tawak-tawak, dan bangsi faktor yang menyebabkan semakin jarang dilaksanakan upacara siar mambang ialah kondisi keagamaan, ekonomi, sistem pengobatan modern.
\end{abstract}

Kata Kunci: Fungsi, Makna, Gubang, Siar Mambang.

\section{A. PENDAHULUAN}

Sumatera Utara terkenal dengan beragam etnik. Dalam kenyataannya etniketnik itu adalah: (a) etnik setempat yang terdiri dari: Melayu, Karo, Pakpak-Dairi, Simalungun, Batak Toba, Mandailing-Angkola, Pesisir, dan Nias; (b) etnik Nusantara seperti: Aceh Raya, Alas, Gayo, Tamiang, Aneuk Jamee, Minangkabau, Banjar, Sunda, Jawa, Bugis, Makasar, dan lainnya; dan (c) etnik-etnik dunia, seperti: Hokkian, Hakka, Khek, Kwong Fu, Tamil, Hindustani, Arab, Pashtun, dan lainnya. Mereka berinteraksi dalam suasana multikultural dan integrasi sosial dalam bingkai Negara Kesatuan Republik Indonesia.
Dari berbagai etnik yang terdapat di Provinsi Sumatera Utara tersebut yang menarik perhatian penulis, untuk dikaji adalah etnik Melayu. Berdasarkan wilayah budaya mereka ini, maka pada umumnya berada di kawasan pesisir. Oleh karena itu orang-orang Melayu di Sumatera Utara sering disebut juga sebagai masyarakat pesisir Sumatera Timur.

Sebagai daerah yang majemuk dan beranekaragam suku, Sumatera Utara sangat berkaitan erat dengan interaksi antar penduduk asli dan penduduk pendatang. Sumatera Utara terdiri dari 8 (delapan) etnis asli dan beberapa etnis yang pendatang dan mendiami daerah di Sumatera Utara. Dengan kebudayaan yang 
begitu majemuk ini, sampai saat ini, Sumatera Utara tidak memiliki budaya yang dominan. Mereka hidup segregatif disatu sisi dan integritas di sisi lain. Para pendatang ini melakukan pola migrasi. Istilah migrasi menurut Takari (2009), "Dapat didefinisikan sebagai gerakan pindah pendudukan dari suatu tempat ke tempat lainnya dengan maksud mencari nafkah atau menetap. Migrasi tersebut ada yang terjadi karena didatangkan oleh seseorang atau suatu lembaga, dan ada juga yang terjadi berdasarkan kemauan sendiri."

Sebagai wilayah yang tingkat migrasi cukup besar, menjadikan Sumatera Utara sebagai tempat pencarian suaka bagi para imigran dari daerah-daerah lain untuk memilih bertahan hidup. Hal ini juga berdampak pada semua aspek kehidupan yang ada di Sumatera Utara itu sendiri. Melayu pesisir yang luput dari arus migrasi yang tinggi juga terkena dampaknya baik dari kebudayaan, adat dan aspek kehidupan lainnya.

Di Indonesia, jumlah suku Melayu sekitar 15\% dari seluruh populasi, yang sebagian besar mendiami propinsi Sumatera Utara, Riau, Kepulauan Riau, Jambi, Sumatera Selatan, Bangka Belitung, dan Kalimantan Barat. Meskipun begitu, banyak pula masyarakat Minangkabau, Mandailing, dan Dayak yang berpindah ke wilayah pesisir Timur Sumatera dan pantai Barat Kalimantan, mengaku sebagai orang Melayu. Selain di Nusantara, suku Melayu juga terdapat di Kota
Tanjungbalai. Suku Melayu ini memiliki kesenian-kesenian yang mendukung identitas kebudayaannya.

Kesenian Melayu kaya akan bentukbentuk ketradisian dengan pola beragam baik dalam seni pertunjukan maupun seni rupa, yang menjadi ciri khas dari daerahnya. Salah satu kesenian yang sangat memperkuat jadi diri masyarakat Melayu adalah seni musik dan seni tarinya. Musik dan tarian Melayu sangat berkembang baik di Sumatera Utara, khususnya di Kota Tanjungbalai. Hal yang menjadikan seni musik dan seni tari Melayu semakin kuat dan mentradisi adalah karena adanya pekerja seni atau seniman yang terus menjaga, melestarikan dan mengembangkan kesenian tersebut. Seniman tidak hanya bertugas untuk menciptakan karya-karya seni yang bagus, tetapi seniman juga harus memiliki pemikiran bahwa karya seni yang ia ciptakan harus mengangkat sebuah tradisi yang nantinya akan tetap diingat oleh masyarakat penikmat dan pendukung seni.

Musik merupakan salah satu media ungkap kesenian yang menjadi salah satu dari unsur kebudayaan yang universal. Musik mencerminkan kebudayaan masyarakat pendukungnya, dimana terkandung nilai-nilai dan norma-norma yang menjadi bahagian dari proses enkulturasi budaya, baik dalam bentuk formal maupun informal. Hampir di seluruh wilayah Indonesia mempunyai seni musik tradisional yang khas. Keunikan tersebut bisa dilihat dari teknik permainannya, penyajiannya 
maupun bentuk (organologi) instrumen musiknya. Hampir seluruh seni tradisional Indonesia mempunyai semangat kolektivitas yang tinggi sehingga dapat dikenali karakter khas masyarakat Indonesia, dengan bentuknya yang khas, baik dari sudut struktural maupun genrenya dalam kebudayaan. Demikian juga yang terjadi pada musik dalam kebudayaan masyarakat Melayu Sumatera Utara, dimana musik juga digunakan dalam mengiringi tarian, menggunakan instrumen daerahnya sendiri sesuai dengan tari yang diringi (Wiflihani \& Suharyanto, 2014).

Musik dan tari di Indonesia, biasanya berkaitan erat dengan upacara- upacara kematian, perkawinan, kelahiran, serta upacara keagamaan dan kenegaraan. Bunyi-bunyian dan nada-nada yang dihasilkan sangat memungkinkan untuk mendukung upacara budaya (ritual) (Prastiawan \& Suharyanto, 2014). Di beberapa daerah, bunyi yang dihasilkan oleh instrumen atau alat tertentu diyakini memiliki kekuatan magis (Suharyanto, 2012). Oleh karena itu, instrumen seperti itu dipakai sebagai sarana kegiatan adat masyarakat. Dari penjelasan di atas maka dapat dikatakan bahwa musik tradisional dapat berfungsi sebagai sarana dalam suatu upacara budaya (ritual).

Sampai saat ini masyarakat kota Tanjungbalai, masih melaksanakan kegiatan berupa upacara-upacara adat tradisional yang masih kuat melekat di kalangan mereka, dalam acara adat seperti adat perkawinan, sunat rasul/khitanan, penabalan anak (aqiqah), dan memperingati hari-hari besar. Dalam menyelengarakan kegiatan-kegiatan adat, masyarakat Kota Tanjungbalai menampilkan berbagai kesenian, seperti nyanyian Didong, nyanyian Sinandong, tari Patam-patam, tari Gubang, dan tari lainnya.

Kesenian Gubang di desa ini merupakan kesenian tradisional yang hidup dan berkembang dalam masyarakat Melayu. Kesenian ini berpatokan kepada nilai-nilai dan aturan tradisi, dan menjadi musik hiburan yang tidak diketahui siapa penciptanya. musik gubang merupakan musik rakyat yang berasal dari kalangan nelayan suku Melayu Asahan. Beberapa penelitian yang telah dilakukan oleh Rahayu, (2005) Satria, (2013). Wiflihani, et.al (2019a);(2019b); (2020), sangat membantu memberikan referensi untuk mengetahui secara pustaka, keberadaan tradisi Gubang di tengahtengah masyarakat pemiliknya. Menurut keterangan para informan, musik ini diperkirakan berasal dari Sungai Paham, Kecamatan Sungai Kepayang.

Keberadaan tradisi Gubang di tengahtengah masyarakat pemiliknya semakin lama semakin memprihatinkan. Regenerasi terhadap pemain musik maupun penari Gubang sangat minim pada saat sekarang ini. Minat masyarakat untuk menggunakan tradisi gubang juga menurun, karena masyarakat Tanjungbalai pada masa sekarang ini mereka lebih cenderung mempergunakan alat band 
sebagai hiburan pada upacara perkawinan, sunat rasul dan penyambutan tamu.

\section{B.METODE PENELITIAN}

Metode digunakan untuk mendapat data yang benar serta tujuannya. Metode merupakan cara yang telah ditentukan untuk memecahkan suatu masalah. Semakin baik suatu sistematis metode, maka pencapaian tujuan penelitian semakin efektif Sugiyono (2012). Pelaksanaan penelitian ini dilakukan dengan menggunakan metode kualitatif dengan pendekatan deskriptif. $\mathrm{Hal}$ ini dimaksudkan untuk menggali data yang masih ada, untuk memperoleh informasi dalam penelitian ini. Penelitian budaya pada prinsipnya merupakan penelitian yang pengkajiannya cukup detail. Namun juga tidak berarti penelitian budaya itu merupakan hal serba sulit. Penelitian budaya tidak harus dilakukan oleh antropolog, sejarawan, arkeolog, budayawan dan sejenisnya. Penelitian budaya boleh dilakukan oleh siapa saja, karena yang paling penting dalam penelitian budaya adalah penguasaan atas metode dan metodologi (Endraswara, 2006)

Wawancara dilakukan kepada pemusik dan tokoh adat pada upacara pengobatan kota Tanjungbalai, Pemusik: 5 orang, Penari: 2 orang, Tokoh adat: 1 orang dan Masyarakat: 5 orang. Wawancara merupakan pengumpulan data yang sangat jelas, sebab melalui wawancara dapat ditanyakan secara langsung bagaimana sebenarnya bentuk penyajian dan bentuk musik/struktur lagu Gubang sebagai musik pengiring tari dan upacara Siar Mambang di Tanjungbalai. Wawancara dilakukan kepada satu orang pemusik, satu orang tokoh adat, satu orang penari, satu orang kepala desa dan satu orang pemuda yang hadir dalam acara pesta tersebut.

\section{C.HASIL DAN PEMBAHASAN}

\section{Tata Pelaksanaan Ritual Upacara Siar Mambang Di Kota Tanjungbalai}

Upacara siar mambang merupakan salah satu upacara adat tradisional melayu yang dilaksanakan masyarakat Tanjungbalai. Upacara ini pada umumnya dilaksanakan pada upacara pengobatan. Dalam penelitian ini, penulis meneliti bagaimana proses pelaksanaan upacara siar mambang yang dilaksanakan pada upacara pengobatan.

Tahapan yang dilaksanakan yaitu: pertama adalah Tahap Membuka Lawang, Yang dimaksud dengan membuka lawang ialah membakar kemenyan di pedupaan upacara pemanggilan, dengan mengelilingi ruangan sambil membawa dupa sebanyak tiga kali yang artinya disinilah dupa yang berisi kemenyan dapat menerangi tempat pelaksanaan upacara. Kemudian dukun menaburkan bunga dan beras tiga warna dimana upacara yang akan dilaksanakan dapat direstui. Dengan diiringi musik, dukun mulai membaca mantera siar mambang dalam pengobatan.

Mantera ini disampaikan oleh sang dukun untuk memanggil roh gaib (Mambang) 
agar dapat segera masuk kedalam tubuhnya.

Kemenyan mulai dibakar di dalam dupa, diiringi dengan musik gubang yang dimainkan oleh pemusik.Kemudian dukun mulai bergerak menari-nari sambil mengelilingi gobuk (periuk tanah) dan balai (tempat pulut dan terawal atau bunga telur) yang disusun dan dilengkapi juga dengan peralatan yang lain. Di sini gerakan dukun hanyalahtergantung kepada roh halusatau mambang yangdatang karena, kualitas gerak bukan menjadi syarat, akan tetapimakna simbolisyang lebih diutamakandidalam upacara ini. Bilamana gerakan ini terhenti maka sang dukun kembali membakar kemenyaan dipedupaan.

Tahap kedua adalah tahap kerasukan, Pada saat asap kemenyan mengepul, dukun mulai kerasukan hal ini dapat dilihat dari gerakan-gerakan yang mulai tidak beraturan dan dilihat juga dari iringan musik yang mulai kencang menandakan disinilah Mambang mulai masuk ke dalam dirinya.Gerakan dukun selanjutnya adalah menimang-nimang mayang pinang (bunga pinang yang terbungkus), gerakan ini menceritakan bahwa seseorang yang sakit butuh pertolongan.

Tahap ketiga adalah Tahap Kesadaran. Masa klimaks ini ditandai dengan mulainya dukun tumbang atau jatuh tapi masih tetap belum sadarkan diri. Disinilah terjadi komunikasi anggota keluarga yang mempunyai maksud dapat bertanya kepada mambang apa yang diinginkannya atau diminta, untuk mengembalikan kondisi yang sakit sebagaimana diharapkan. Sampai pembicaraan itu selesai akhirnya mambang pergi dari tubuh si dukun, kemudian pengiring atau yang membantu si dukun mengucapkan mantera untuk mengembalikan mambang ketempat asalnya sambil menyapukan kain keseluruh tubuh dukun agar segera sadar.

\section{Fungsi Lagu Gubang Dalam Upacara Siar Mambang}

Fungsi lagu sebagai sarana upacara adat di indonesia, biasanya berkaitan erat dengan upacara-upacara kematian, perkawinan, kelahiran, serta upacara keagamaan dan kenegaraan. Bunyi-bunyian dan nada-nada yang dihasilkan sangat memungkinkan untuk mendukung upacara budaya (ritual). Dari penjelasan di atas maka dapat dikatakan bahwa musik tradisional dapat berfungsi sebagai sarana dalam suatu upacara budaya (ritual). Seperti yang disebutkan Alan P.Merriam (1964) fungsi komunikasi. Musik memiliki fungsi komunikasi berarti bahwa sebuah musik yang berlaku disuatu daerah kebudayaan mengandung isyarat-isyarat tersendiri yang hanya diketahui oleh masyarakat pendukung kebudayaan tersebut. Hal ini dapat dilihat dalam bentuk penyelenggaraan upacara siar mambang dengan menggunakan lagu Gubang.

Mantra atau syair gubang berfungsi untuk menuju memanggil mahluk-mahluk diluar dimensi manusia. Syair-syair pada gubang menyebutkan titian mahluk diluar dimensi 
tersebut sehingga menghubungkan dimensi langsung pada manusia yang menyanyikan syair-syair pada lagu-lagu tersebut. Manteramantera yang biasanya dinyanyikan dapat dilihat dibawah ini :

Konon manopi-nopiiiiiiiii iiiiii/ Singgah sabontar mangambek putat/Kalaulah sudah nasib tidak rajokiiiiiiiiii iiiiiiiiiii/Lagi dimulutn bisa malumpat

Oiiiiiiiiiiii hoiiiiiiiiiiiii iiiiiiiiiiii//Kualolah bubul sinandong oiiiiiiiiiiii iiiiiiiiii

Oiiiiiiiiii dokatlah sijabot/Dokat sijabot/Oiiiiiiiiiii sijumpo lahoiiiiiiiii/Orang balah dangoiiiiiiiiii

Oiiiiiiiiiiii oiiiiiiiiiii sinandong oiiiiiiiiii/Satitik lah ombun/Satitik ombun sinandong oiiiiiiiiiii

Oiiiiiiiiiiii jabut datang lah/Oiiiiiiiiiii sinandong oiiiiiiii/Oiiiiiiiiiii sampek sekarang hadang galombang oiiiiiiiiiiiii/Jadi lah galombang oiiiiiiiiiiiiiii Oiiiiiiiiiiiiii sampek sekarang/Oiiiiiiiiiiiiii ombak sinandong asahan oiiiiiiiiiiii

Sampai sekarang gubang pada masyarakat Melayu Tanjungbalai berfungsi untuk upacara pengobatan tradisional yang disebut dengan Siar Mambang. Tujuan utama pengobatan ini adalah untuk mengobati penyakit yang dianggap akibat dari perbuatan mahluk halus, seperti hantu, jin, jembalang, polong, maupun mambang.

Dalam pelaksanaan upacara siar mambang (pengobatan tradisional) orang yang sakit dapat sembuh kembali dengan memainkan gubang. Gubang merupakan lagu yang dapat menciptakan suasana trance (kemasukan roh). Orang yang kemasukan roh mahluk halus tersebut adalah seorang pawang.
Biasanya pawang memakai selempang untuk diikatkan dibagian pinggangnya, dan mulai upacara dengan memainkan lagu gubang serta panandong pun mulai bernyanyi. Setelah itu pawangpun kemasukan mambang yang kemudian berkomunikasi dengan orang yang mengerti dengan bahasa roh halus (biasanya pengawal pawang) yang kemudian pengawal pawang tersebut akan memberitahukan apa yang menjadi obat atau ramuan yang akan diminum oleh orang sakit tersebut.

Proses dalam upacara siar mambang biasanya dilakukan oleh seorang pawang. Sebelum upacara tersebut dilaksanakan pawang harus melaksanakan puasa terlebih dahulu, dan mempersiapkan mantera yang akan diucapkan sewaktu upacara berlangsung. Ketika lagu gubang dimainkan pawang pun mulai bersip-siap. Pada awal gubang dimainkan ritem atau dengan tempo yang semakin cepat dan dinamik yang semakin kuat sehingga dapat mempengaruhi pikiran dan kesadaran seorang pawang sehingga membuat pawang tidak sadarkan diri atau kemasukan (trance) dan mulai menggoyangkan tubuhnya (menari). Dalam hal ini syair gubang turut memacu sipawang kemasukan. Caranya syair gubang dinyanyikan secara terus menerurus dengan tempo yang semakin cepat yang dibarengi dengan mantera. Musik dan syair saling berhubungan atau saling mendukung membuat sipawang kemasukan roh. Alat-alat musik di dalam rekontruksi Siar Mambang dimainkan seara 
ensambel. Ensambel musik gubang yang dipakai di dalam rekontruksi upacara Siar Mambang terdiri dari.

Gendang, Gendang anak atau gendang peningkah merupakan alat musik gendang dibuat dari kulit binatang seperti kambing, lembu atau kerbau. Gendang melayu biasanya digunakan dalam mengiri tari-tarian, pertunjukan musik melayu yang tergabung dalam orkes melayu. Dalam musik gubang, gendang melayu merupakan alat musik yang menjadi improvisasi musik. Dalam komposisi musik gubang, instrumen gendang melayu mengiringi musik tidak berdasarkan pola yang ditentukan. Instrumen gendang mulai dimainkan ketika sang pawang telah mulai dirasuki oleh mambang. Gendang anak atau gendang paningkah merupakan alat musik gendang yang dibuat dari kulit binatang seperti kambing atau lembu. Gendang melayu biasanya digunakan dalam mengiring taritarian, pertunjukan musik melayu yang tergabung dalam orkes melayu. Dalam komposisi musik gubang, instrumen gendang melayu mengiringi musik tidak berdasarkan pola yang ditentukan. Instrumen gendang mulai dimainkan ketika pola ritem gendang melayu dalam iringan musik gubang tidak menentu sesuai pola musik yang diinginkan sang pawang.

Tawak - Tawak, Tawak-tawak merupakan gong kecil yang digunakan sebagai tempo dalam iringan gubang. Bentuk tawaktawak sama seperti gong biasa. Sebutan tawak-tawak berasal dari kata tetawak yang berasal dari bahasa Melayu pesisir. Alat musik tawak-tawak berbentuk gong yang berukuran lebih besar jika dibandingkan dengan canang, namun lebih kecil jika dibandingkan dengan gong. Dalam musik gubang, masyarakat Tanjungbalai menyebut bahwa tawak-tawak berfungsi sebagai gong. Oleh karena itu, tawak-tawak lazim disebut dengan gong kecil, tawak-tawak yang dipakai oleh pemusik gubang lebih banyak daripada yang dipakai oleh musik lainnya.

Bangsi, Bangsi merupakan alat musik tiuop yang berfungsi sebagai alat pembawa melodis dalam sebuah komposisi musik gubang untuk. Dalam iringan musik gubang, bangsi menjadi alat melodis yang mengiringi alunan ritem yang dimainkan oleh gendang sebagai tempo musik.

\section{Makna Lagu Gubang}

Gubang memiliki sebuah makna yang sangat penting dan juga unik, terutama bagi masyarakat Melayu yang berada di Tanjungbalai. Menurut Harimurti (2001), "menjabarkan pengertian makna sebagai pengaruh penerepan perilaku manusia pada suatu presepsi yang dilaksanakan yang mengandung nilai".

Mulyana (2004), "Nilai adalah keyakinan yang membuat seseorang atau manusia bertindak atas dasar pilihannya. Sesuai dengan pendapat tersebut maka pengertian makna lagu gubang dalam upacara 
siar mambang dapat disimpulkan pengertian makna mempunyai nilai-nilai dan pesan dalam syair atau mantra.

Pada masa sekarang, masyarakat Melayu pesisir Tanjungbalai secara mayoritas tidak berkenan melaksanakan upacara siar mambang, karena berhubungan dengan masuknya agama islam, masyarakat ini semakin memahami tentang kaidah-kaidah yang berlaku di dalam agama tersebut.

Kencendrungan

pergeseran

pandangan keagamaan di desa ini terjadi karena pemurnian islam dan pandangan dari sudut moral. Artinya setiap upacara religi maupun adat selalu diselaraskan dengan memohon kehadiran Allah SWT semoga segala sesuatu di jauhkan dari malapetaka. Hala ini masi dapat dilihat pada upacara siar mambang yang dilakukan oleh dukun, ssebelum membaca mantra selalu di mulai dengan kata basmalah dan diakhiri dengan alhamdulillah. Penggalan dan makna dari setiap syair mantera gubang dalam upacara siar mambang :

Konon manopi-nopiiiiiiiii iiiiii/Singgah sabontar mangambek putat/Kalaulah sudah nasib tidak rajokiiiiiiiiii iiiiiiiiiii/Lagi dimulut bisa malumpat

(Yang bermakna, suatu cerita atau perumpamaan sebuah keinginan yang kita inginkan yang mungkin terjadi bisa berubah seperti yang tidak kita harapkan)

Oiiiiiiiiiiiii hoiiiiiiiiiiiiii iiiiiiiiiiiiii/Kualo lah bubul sinandong oiiiiiiiiiiii iiiiiiiiii
Yang bermakna, sebuah harapan disuatu tempat dimuara.

Oiiiiiiiiii dokatlah sijabot/Dokat sijabot/Oiiiiiiiiiii sijumpo lahoiiiiiiii/Orang balah dangoiiiiiiiiii/Oiiiiiiiiiiii oiiiiiiiiiii sinandong oiiiiiiiiii/Satitik lah ombun/Satitik ombun sinandong oiiiiiiiiiiii

(Yang bermakna, ratapan seseorang yang berharap jumpa atau berharap sampai kesuatu tempat itu dengan usaha yang gigih)

Oiiiiiiiiiiii jabut datang lah/Oiiiiiiiiiii sinandong oiiiiiiiii/Oiiiiiiiiiii sampek sekarang hadang galombang oiiiiiiiiiiiii/Jadi lah galombang oiiiiiiiiiiiiiii (Yang bermakna, walaupun banyak rintangan pencobaan yang menghadang tidak meatahkan semangat untuk mencapai suatu tujuan)

Oiiiiiiiiiiiiii sampek sekarang/Oiiiiiiiiiiiiii ombak sinandong asahan oiiiiiiiiiiii

(Yang bermakna, ombak dilautan asahan tetap bergelombang)

Berdasarkan kesimpulan makna dari setiap syair pada lagu gubang adalah Suatu cerita dalam kehidupan manusia tetap tidak terlepas dari cobaan atau rintangan yang tetap menjadi hikmah baik dan buruknya, baik dalam suatu pekerjaan, bermasyarakat, maupun dengan sang pencipatanya. Semua apa yang kita inginkan belum menjadi seperti apa yang kita harapkan, usaha dan semangat lah yang, membuat kita terus yakin dan berusaha mewujudkan salah satu apa yang kita harapkan. 
Musik gubang adalah musik kesukaan roh halus yang banyak menolong mereka dalam menjalani hidup seperti menyembuhkan penyakit, menjauhkan tanaman pertanian mereka dari serangan hama dan membantu mereka untuk mendapatkan hasil tangkapan ikan yang lebih banyak. Musik gubang ini tercipta dan juga dimainkan khusus untuk mengiringi proses segala upacara masyarakat Tanjungbalai yang membutuhkan hadirnyamambang (roh halus). Dalam hal ini pada upacara siar mambang musik gubang yang merupakan musik kesukaan mambang berperan sangat penting karena tanpa musik tersebut mambang tidak akan hadir pada upacara tersebut. Upacara siar mambang yang merupakan upacara penyembuhan sangat membutuhkan hadirnya mambang yang mereka percayai dapat menyembuhkan penyakit yang mereka derita.

Kata gubang berasal dari sebuah cerita dimana ada tiga nelayan yang terombang- ambing di tengah lautan karena angin tidak berhembus. Salah seorang nelayan yang mulai putus asa mulai meniup bangsi (sejenis seruling), mengalunkan musik ratapan tentang nasib perjalanan mereka dan seorang nelayan lainnya menjerit kealam bebas minta pertolongan datangnya angin .

Ternyata usaha para nelayan tersebut berhasil. Angin yang semula mati perlahanlahan kembali berhembus dan layar kembali terkembang. Tali temali untuk memperkuat tiang berdengung. Karena kegembiraannya nelayan yang duduk di bagian belakang perahu, secara spontan memukul dinding perahu sambil bernyanyi. Nelayan yang duduk di depan perahu tak kalah senangnya, dan ia segera mengiringi nyanyian dengan bangsi.

Tiupan bangsi, dengungan tali temberang, ditambah dengan pukulan tangan pada dinding perahu menimbulkan suatu musik. Karena kejadian ini timbulnya diatas perahu, dalam bahasa melayu dialek asahan disebut dengan gebeng, maka musik ini disebut dengan musik gebeng, yang lama kelamaan di kenal dengan musik gubang. Bangsi dalam ansambel berfungsi sebagai pembawa melodi utama, dalam ansambel gubang bangsi hanya dimainkan satu buah saja. Gendang dimainkan oleh tiga orang. Tawak-tawak dimainkan oleh satu orang dengan ritem konstan.

Berdasarkan penjelasan di atas dapat disimpulkan bahwa musik dan syair gubang adalah sesuatu yang sangat penting dalam mengiringi upacara siar mambang yaitu pada tarian kemasukan.

Tanggapan Masyarakat Melayu Tanjungbalai Terhadap Fungsi dan Makna Lagu Gubang Dalam Upacara Siar Mambang.

Ada beberapa tanggapan masyarakat Tanjungbalai mengenai gubang dan upacara siar mambang. Bagi peneliti itu merupakan masukan yang positif dan tidak menjadi bahan permasalahan dalam penelitian. 
Banyak tanggapan positif yang disampaikan masyarakat dalam wawancara, salah satunya wawancara yang bernilai positif disampaikan oleh Bapak Agustoni (Tanjungbalai 21 september 2016), yang mengatakan bahwa ada perbedaan upacara siar mambang di Asahan dengan di daerah Melayu lainnya, karena setiap daerah sudah memiliki tata cara pelaksanaan adat masingmasing. Beliau juga mengatakan gubang dan upacara siar mambang sangat perlu untuk dilestarikan karena sudah mulai dilupakan dan tertinggal karena alat musik modern dan lagulagu band, sehingga generasi muda tidak mau lagi belajar baik mendengarkan tradisi musik gubang.

Bapak deri/pemain gendang mengatakan agar setiap keluarga keturunan Melayu hendaknya selalu menggunakan musik gubang dalam setiap upacara adat yang sakral, agar sekaligus memperkenalkan kepada keturunan berikutnya bagaimana sebenarnya kebudayaan adat melayu yang sesungguhnya dan kebudayaan itu tidak hilang begitu saja.

Tanggapan yang berbeda diungkapkan oleh seorang pemuda yang hadir pada acara tersebut yang bernama Mardi selaku warga Tanjungbalai, upacara siar mambang bukanlah hal yang wajib dilakukan oleh masyarakat Melayu Tanjungbalai. Alasan beliau ialah karena sebagai manusia yang sudah mengenal agama sebaiknya kita menyampaikan sesuatu kepada Tuhan tidak dengan cara mengadakan upacara adat semata, namun dengan beribadah. Walaupun beliau berkata begitu bapak Umar $S$ tetap menghimbau kepada generasi muda untuk mempelajari semua budaya yang ada di daerah Melayu agar adat istiadat yang diwariskan oleh nenek moyang tidak punah dan selalu tetap dilestarikan.

Ibu Mita selaku penari mengatakan perlu diadakan upacara siar mambang, agar selain melestarikan kebudayan adat Melayu Tanjungbalai, juga semakin mendekatkan hubungan sosialisai antara masyarakat setempat.

Bapak habibi selaku tokoh adat di kota Tanjungbalai mengatakan, bukan hanya generasi muda, bahkan orang tua yang sudah lama diperantauanpun mungkin tidak mengetahui apa itu gubang dan apa itu siar mambang. Suatu hal yang memalukan jika seseorang tidak mengetahui adat istiadatnya, sementara diantara suku di negara ini suku Melayu adalah suku yang sangat kental adatistiadatnya.

Beliau juga menambahkan bahwa upacara ini sudah mulai jarang dilakukan oleh masyarakat suku Melayu kususnya di Tanjungbalai. Faktor Agama, Pada masa sekarang, masyrakat Melayu pesisir Asahan secara mayoritas tidak berkenaan melaksanakan upacara siar mambang, karena berhubungan dengan masuknya agama Islam, masyarakat ini semakin memahami tentang kaidah-kaidah yang berlaku di dalam agama tersebut. 
Sebagai masyarakat Melayu, warga masyarakat ini mulai memahami Islam murni, dikarenakan banyak anggota masyarakat tersebut berpendidikan agama yang lulusan dari pondok pesantren yang ada disekitar kecamatan tersebut. Sehingga mereka yang telah mendalami islam dapat memberikan penerangan dan pengetahuan kepada orangorang disekitarnya.

Dalam kurun waktu sekitar 2008 masyarakat Malayu pesisir Asahan ini sudah jarang melakukan upacara siar mambang, kalaupun ada upacara ini dilakukan hanya sebagai pengobatan yang pergi ke dukun dengan tidak memakai persyaratan yang utuh lagi.

Faktor Ekonomi, Biaya yang digunakan untuk melakukan upacara adat istiadat Melayu Pesisir Asahan, terutama upacara siar mambang membutuhkan biaya yang sangat besar. Mulai dari biaya membuat lancang, membuat perlengkapan syarat-syarat upacara, membuat acara makan bersama, memanggil kelompok kesenian, dan membayar dukun. Keluarga yang memiliki keterbatasan jarang atau bahkan tidak melakukan upacara siar mambang di dalam upacara adat yang mereka adakan.

Faktor Sistem Pengobatan Modern, Upacara siar mambang merupakan salah satu cara atau media pengobatan bagi masyarakat Melayu Asahan. Pengobatan ini dilakukan sebagai pengobatan untuk mengusir roh-roh jahat yang merasuk kedalam tubuh manusia.
Cara pengobatan ini dilakukan apabila ada warga yang sakit akibat guna-guna maupun penyakit keturunan.

Dengan adanya puskesmas didaerah tersebut sistem pengobatan yang tadinya melalui dukun kini berganti dengan dokter. Ini disebabkan karena sosialisasi dari bidang kesehatan kepada masyarakat cukup manjur dan harga perobatan lebih murah sehingga masyarakat lebih suka berobat ke dokter bukan ke dukun.

Dan juga dapat dilihat pada perubahan pola pikir masyarakat bahwa kesadaran akan teknologi dengan persentuhan dunia modern akan membawa mereka kepada manusia yang beradab.

\section{SIMPULAN}

Upacara siar mambang adalah salah satu bentuk upacara ritual bagi masyarakat di daerah Tanjung Balai. Siar Mambang muncul dalam bentuk upacara pemujaan terhadap mambang. Upacara ini dilakukan apabila ada warga desa yang sakit diakibatkan guna-guna maupun penyakit keturunan. Fungsi gubang dalam upacara siar mambang adalah sebagai sarana untuk mencapai keadaan trance pada dukun yang memimpin upacara. Makna gubang adalah sebagai suatu musik atau media yang harus dimainkan agar roh halus atau mambang mau hadir dan melakukan penyembuhan, karena gubang merupakan musik kesukaan dari roh halus atau mambang tersebut. Berbagai macam tanggapan 
masyarakat Melayu yang berada di Kota Tanjung Balai mengenai Gubang pada upacara

Siar Mambang. Ada yang menyebutkan ritual ini supaya tetap dilaksanakan karena merupakan budaya yang perlu untuk dilestarikan. Namun ada beberapa yang berpendapat upacara ini tidak lagi terlalu penting untuk dilaksanakan karena sudah hampir semua masyarakat Melayu di Kota Tanjung Balai sudah menganut agama. Keadaan ekonomi keluarga juga merupakan penyebab Upacara Siar Mambang ini semakin jarang dilaksanakan.

\section{DAFTAR PUSTAKA}

Budilinggono. (1993). Bentuk dan Analisis Musik. Jakarta: Mahendra Sampana.

Ellfeldt. L. (1995). Dance from magic to art, terjemahan Daryono.Yogyakarta: Pasca Sarjana UGM.

Esdawara. S. (2006). Penelitian Kebudayaan, Yogyakarta. Pustaka widyatama.

Harimuti. K. (2001). "Paradigma semiotik dalam linguistik Melayu/Indonesia"

Koentjaraningrat. (1985). Beberapa pokok antropologi sosial. Jakarta: Dian Rakyat

Merriam. A.P. (1964). The antropologhy of musik. Chicago: the university of arizona press.

Moleong, L. J. (2006). Metodologi Penelitian Kualitatif. Bandung. Remaja Rosdakarya.

Mulyana. R. (2004). mengartikulasikan Pendidikan Nilai. Bandung. Alfabeta

Panggabean. R.T. (1993). Deskripsi Tradisi Gubang Asli dan Lukisan'. Skripsi: Universitas Sumatera Utara.

Poerwadarminta, W.J.S. (1976). Kamus Umum Bahasa Indonesia. Jakarta: Balai Pustaka

Prastiawan, I \& Suharyanto, A. (2014). Sejarah tari. Unimed Press.

Rahayu, T. (2005). Upacara Adat Siar Mambang di Kabupaten Asahan. Medan. Tesis: Unimed.

Satria. H. (2013). Tinjauan Varian Ritme Musik Gubang di Tanjung Balai Asahan. Skripsi: FBS Unimed

Sugiyono. (2008). Metode Penelitian Kuantitatif kualitatif dan R\&D. Bandung Alfabeta.

Sugiyono. (2009). Metode Penelitian Kuantitatif kualitatif dan R\&D. Bandung Alfabeta.

Sugiyono. (2009). Metode Penelitian Pendidikan. Bandung Alfabeta.

Sugiyono. (2010). Metode Penelitian Kuantitatif kualitatif dan R\&D. Bandung Alfabeta.

Sugiyono. (2012). Metode Penelitian Kuantitatif kualitatif dan R\&D. Bandung Alfabeta.

Suharyanto, A. (2012). Makna Gondang dan Tort-tor dalam Upacara Ritual Parmalim Nasiak Bagi di Hutatinggi Laguboti Toba Samosir, dalam Apresiasi Simbol dalam Seni Nusantara 1, 59-73, Bandung: CV. WarliArtika

Takari, M. (2009). Kebudayaan Melayu di Sumatera Timur.Medan:USU press.

Wiflihani \& Suharyanto, A. (2014), Teater Tradisional Melayu Makyong dalam Lintasan Sejarah dan Kekinian Di Sumatera Utara. Jurnal Pendidikan IImu-IImu Sosial, 6 (2): 138-143. 
Wiflihani, Pita HD Silitonga, Herna Hirza, (2019a). Digitalization of North Sumatera Malay Ritual Music Using Cubase 5 Software; Budapest International Research and Critics Institute-Journal (BIRCI-Journal), Volume 2, No 4, November 2019, Page: 556-566.

Wiflihani., Silitonga, P.H.D., Hirza, H., (2020), Music in "Gobuk Melayu" Ritual Traditions: Study of Performance Aspects, Forms and Structures. Proceedings of the First Conference of Visual Art, Design, and Social Humanities, CONVASH, 2 November 2019, Surakarta, Central Java, Indonesia, CONVASH, EAI. DOI: 10.4108/eai.2-11-2019.2294720

Wiflihani., Silitonga, P.H.D., Hirza, H., Hakim, I., \& Mukhlis, (2019b), Digitalisasi Musik Iringan Tari Ritual Melayu Sumatera Utara dengan Menggunakan Perangkat Lunak Cubase, Medan: Budapest International Research and Critics University (BIRCUPublishing).

Wilkinson, R.J. (1959). A Malay english dictionary (Romanised). 